\title{
Introduction
}

\section{Language, Memory and the Temporal Lobes}

\author{
Facundo Manes $^{\mathrm{a}, \mathrm{b}, \mathrm{c}, *}$ and Ezequiel Gleichgerrcht $\mathrm{t}^{\mathrm{a}, \mathrm{c}}$ \\ ${ }^{\mathrm{a}}$ Institute of Cognitive Neurology (INECO), Buenos Aires, Argentina \\ ${ }^{\mathrm{b}}$ Laboratory of Cognitive Neuroscience, Universidad Diego Portales, Santiago, Chile \\ ${ }^{\mathrm{c}}$ Institute of Neurosciences, Favaloro University, Buenos Aires, Argentina
}

In recent decades, extensive data have been generated about the normal and pathological functioning of the temporal lobes, and their relationship with speech and semantics. Advancement in this field has contributed to the development of new approaches not only for the assessment of cognitive deficits associated with lesions and degeneration of the temporal lobe, but also for the development of novel techniques that may prove useful in the rehabilitation of language skills. This issue of Behavioural Neurology is dedicated to original research in the field of aphasia and the temporal lobes which was presented during the World Federation of Neurology's Research Group on Aphasia and Cognitive Disorders Meeting held during mid-May 2010 in Istanbul, Turkey. The articles in this issue survey many of these aspects and, taken together, demonstrate the interdisciplinary approach from which the field will benefit the most.

Sebastian Crutch and Elizabeth Warrington build on the phenomenon they refer to as "refractory semantic access dysphasia" by investigating the semantic organization associated with proper names in two global aphasic patients. They delve into the results of cognitive performance in these patients to contribute to the literature on taxonomy and theme-centered organization of proper names. In this same issue, Carlo Semenza critically reviews findings on naming with proper names (mostly person names) and discusses the relevance of the left temporal pole in this respect. Semenza's review provides insight into the discussion of the brain substrates underlying proper name processing and offers also some speculations as to how the brain has evolved

\footnotetext{
*Address for correspondence. E-mail: fmanes@ineco.org.ar.
}

to specifically support the development and retrieval of proper names.

Steven Rapcsak and Emily Edmonds review the functional impairment in face memory that results from frontal and temporal lobe lesions. They propose a model for facial memory processing that requires dynamic interactions between the executive controlled processes and a set of automatic processes that strongly depend on the temporal lobes.

Two articles in this issue are devoted to exploring the relationship between cardiovascular events and temporal lobe functioning. Chris Butler and Adam Zeman investigate the cardiovascular correlates of transient epileptic amnesia, which has been classically associated with temporal lobe epilepsy. Their study constitutes an important contribution to the current literature, as the heart-brain link is one that will result in the design of fundamental strategies for the prevention and treatment of several neurological conditions. Valentina La Corte and collaborators report lesions in sites not previously linked with confabulation, resulting from rupture of an anterior communicating artery aneurism. The unique characteristics of their case provide further details into particular aspects of the mechanisms underlying confabulations.

Anna Basso and Margherita Macis review the stateof-the art of the efficacy of aphasia therapy in chronic patients and report on the effects of intensive hometherapy for a large group of patients with severe chronic aphasic. Their results provide important information that can be readily translatable into specific strategies for treatment of severely aphasic chronic patients.

All articles included in this issue have a clear common denominator: their findings have relevant theoret- 
ical and clinical implications which, incorporated into the scientific literature and embraced by different aspects of patient care, will contribute to the advancement of this growing field. By doing so, we will potentiate the efforts put thus far in offering a better quality of life to patients who are affected by aphasia and other disorders associated with the temporal lobes. 


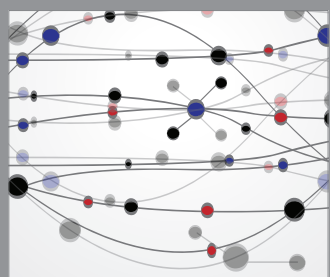

The Scientific World Journal
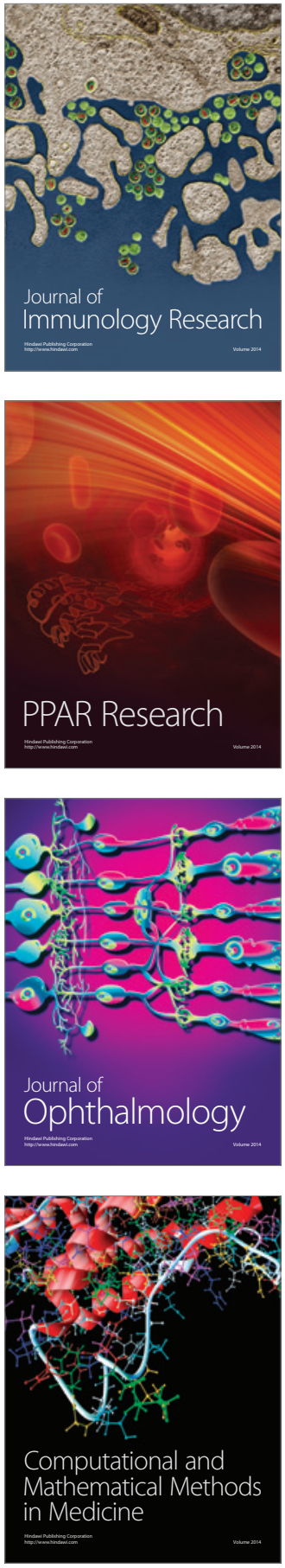

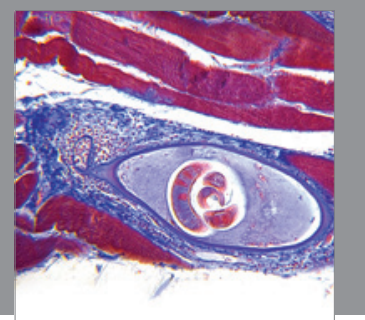

Gastroenterology

Research and Practice
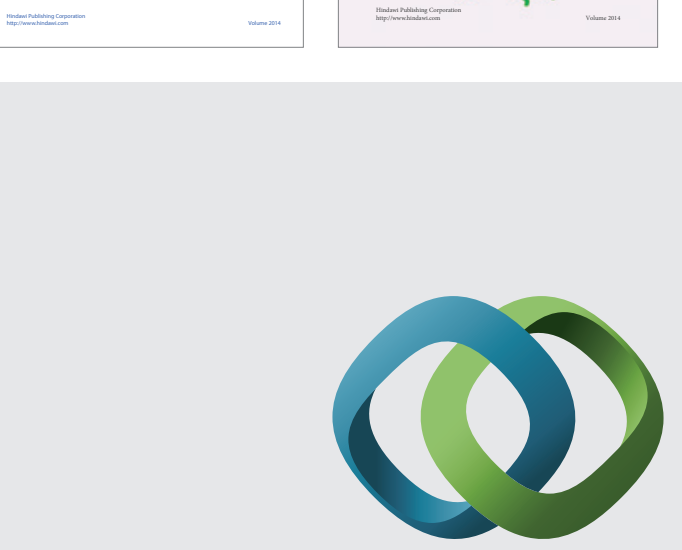

\section{Hindawi}

Submit your manuscripts at

http://www.hindawi.com
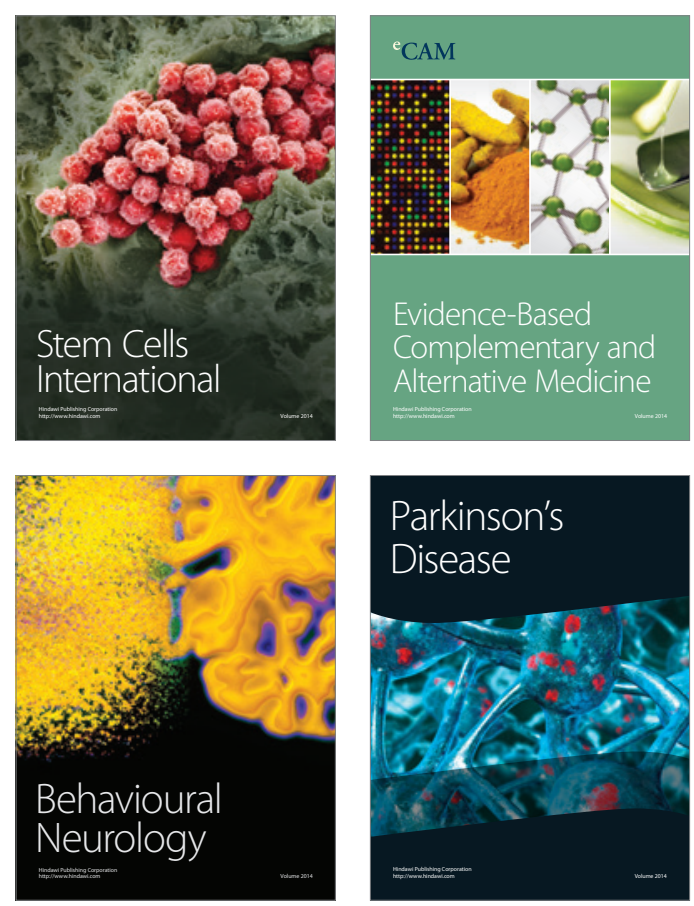

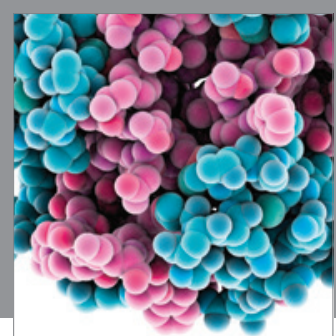

Journal of
Diabetes Research

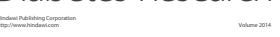

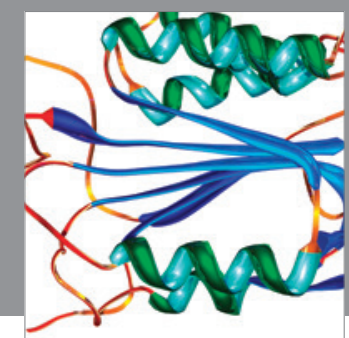

Disease Markers
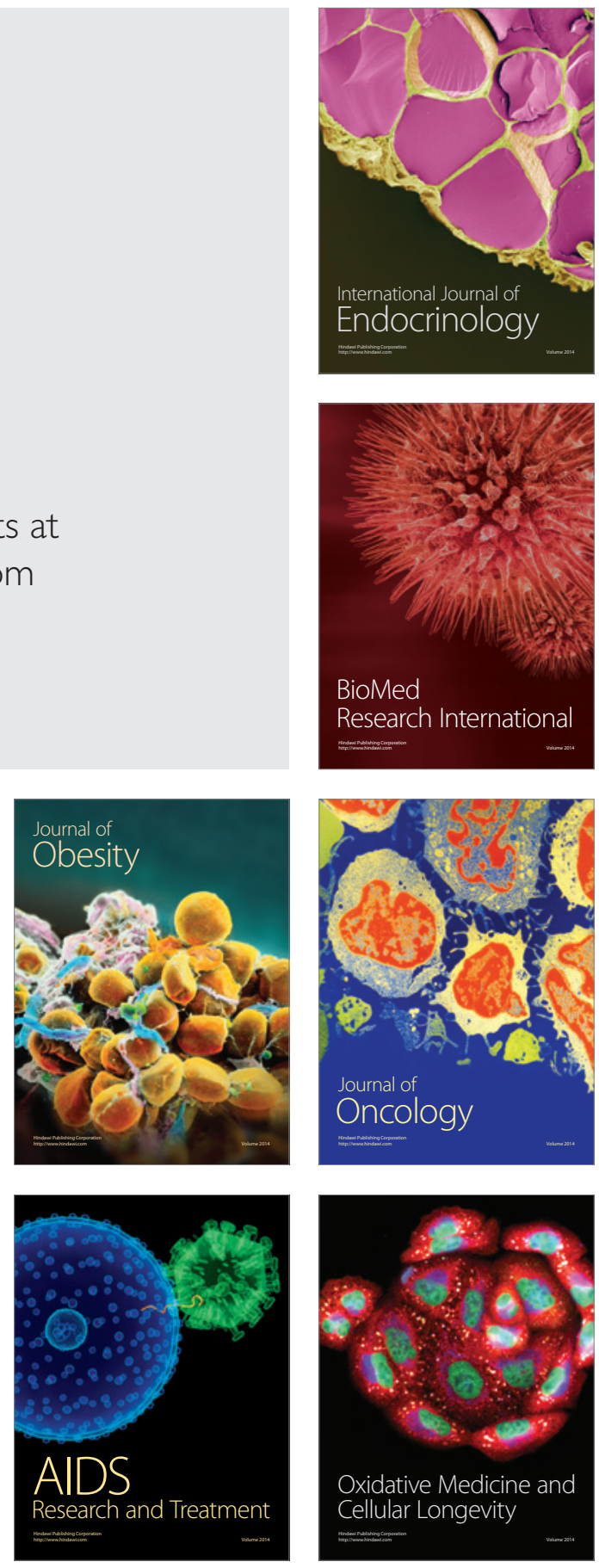